\title{
Quantitative trait loci for internal nematode resistance in sheep: a review
}

\author{
Sonja DOMINIK* \\ CSIRO Livestock Industries, Armidale, NSW, Australia
}

(Accepted: 7 September 2004)

\begin{abstract}
Internal nematode resistance in sheep has a large impact on the economy of sheep industries. Selection for nematode resistance in sheep breeding schemes would help to reduce the direct and indirect cost of parasitism to these industries. However, this is not widely practiced because of the difficulty of measuring parasite resistance or correlated indirect selection criteria. The identification of genes or linked markers that have a significant association with the variance of indicator traits of internal nematode resistance in sheep would facilitate the inclusion of nematode resistance in sheep breeding operations. This review summarises findings reported in the literature of quantitative trait loci for internal nematode resistance in sheep. Issues relating to the analytical and phenotypic complexity of nematode resistance are discussed in the context of the findings of quantitative trait loci for nematode resistance published to date.
\end{abstract}

sheep / internal nematode resistance / quantitative trait loci

\section{INTRODUCTION}

The search for quantitative trait loci (QTL) that significantly contribute to the variance of trait expressions in livestock has been increasingly a focus in the field of livestock genetics. QTL for traits of economical importance and traits that are complicated or expensive to measure and therefore difficult to include in breeding programmes are of primary interest for livestock industries. Internal nematode resistance in sheep is one such trait. It has a large economic impact on the sheep industry and is rather cumbersome and costly to measure.

The economic impact of internal nematodes on the sheep industry has two components. The first component is the direct annual cost of anthelmintic treatment and increased labour for sheep and pasture management, and the second, an indirect cost to the industry that is incurred through production losses in live

*Corresponding author: Sonja.Dominik@csiro.au 
weight, wool, decreased fertility and survival. One of the few estimates of the total annual cost of parasitism was published in 1995 at an estimated cost of \$222 million Australian Dollars to the Australian sheep industry [19]. With the increasing problem of anthelmintic resistance this estimate can be expected to be considerably higher today [15].

Breeding sheep for increased nematode resistance would reduce the cost of anthelmintics and reduce the effect of internal nematodes on production. The difficulty of including nematode resistance in breeding programmes is mainly due to the difficulty of measuring nematode resistance itself. Thus, nematode resistance is recorded and included in breeding programmes through correlated traits; the most widely used being faecal egg count (FEC). This trait is costly to measure and it is necessary to artificially challenge selection candidates with worm larvae to ensure a standardised exposure to internal nematodes across individuals. This technique raises criticism with seed stock producers, because the parasite burden can have negative effects on other production characteristics and the visual appearance of valuable rams can be compromised as a result of the nematode infestation. In addition, the infected animals spread worm eggs, which requires additional attention to paddock management strategies.

The inclusion of resistance to internal nematodes in breeding programmes for sheep would find wider acceptance if QTL or closely linked markers could be identified that are associated with a significant proportion of the variance of nematode resistance traits. If nematode resistance traits were more frequently included in breeding programmes the economic impact of internal nematodes could be reduced as a consequence and the sheep industries would benefit greatly.

The purpose of this paper is to review published research findings on genetic variation and QTL for internal nematode resistance in sheep and to discuss the phenotypic and analytical complexity that has to be considered in current genomic approaches in the experimental set up, analysis and interpretation of the results.

\section{GENETIC VARIATION IN INTERNAL PARASITE RESISTANCE}

The polygenic background of internal nematode resistance has been investigated to determine if genetic progress is feasible in breeding programmes that focus on nematode resistance $[7,15,32,33]$. It has been established that genetic variation in nematode resistance exists between and within sheep breeds. 


\subsection{Between breed variation}

Several studies $[2,16,22,23,30]$ have compared different breeds for their ability to resist internal nematode infections and as a result variation between breeds has been observed. In a comparison of four breeds, the Red Maasai breed showed higher resistance to $H$. contortus than Blackheaded Somali and Dorper sheep [22] and all three breeds were substantially more resistant than the Romney Marsh breed. A study by Baker et al. [2] found significantly different FEC between Dorper and Red Maasai sheep with the Red Maasai breed showing lower FEC following a field infection with $H$. contortus. However, surprisingly no significant differences were established following an artificial challenge with the same nematode species. On the contrary, a different study [30] fully confirmed the results of Mugambi et al. [22] in a comparison of the Red Maasai and the Dorper breed. Wanyangu et al. [30] found that the Red Massai sheep were more resistant to $H$. contortus than Dorpers, by producing lower FEC and higher immunological parameters after artificial infection with the parasite. A comparison between Barbados Black Belly sheep and INRA401 composites demonstrated that Barbados Black Belly have a higher resistance to $H$. contortus and T. colubriformis than the INRA401 [16]. In another study, the Garole breed was recommended for inclusion in composite breeding in a humid region of India rather than the Deccani or the Bannur breed due to its significantly higher internal nematode resistance [23]. However, lambs from Garole sires had lower live weight and lower growth rates.

If QTL or markers that are closely linked to increased resistance can be identified in exotic breeds there is the potential to introgress the favourable gene/s into more profitable breeds to result in an increased nematode resistance without compromising production in the long term [29].

\subsection{Within breed variation}

It has been shown that sufficient genetic variation can be found within flocks of the same breed to make genetic progress through selection for internal nematodes resistance [7, 32, 33]. It was demonstrated that Romneys can be selected divergently for nematode resistance [7] and the same was shown in Merino flocks that were successfully selected for high and low immune response to Haemonchus contortus and Trichostrongylus colubriformis [32,33]. Based on moderate heritability estimates for FEC, Gray [15] pointed out the possibility of breeding Merino sheep for increased internal nematode resistance. In later studies it was confirmed that nematode 
resistance, as measured by faecal egg count (FEC) and packed cell volume (PCV), is moderately heritable. Heritabilities range between 0.23 [32] and 0.41 [33] for FEC and for PCV around 0.20 as indicative phenotypes of resistance [32].

\section{COMPLEXITY OF PARASITE RESISTANCE}

\subsection{Phenotypic complexity}

For several reasons, resistance to internal nematodes is a physiologically complex trait and therefore difficult to measure. Firstly, a large number of physiological pathways are involved in the prevention of the establishment of worms and the development of resistance as a result [6]. Secondly, the pathways that activate immune responses are different depending on the parasite naivety status of the sheep. Due to the physiological complexity, indicator traits might also fail to represent all of the pathways involved in internal nematode resistance.

The key processes of an immune response to internal nematodes control the establishment of cell populations and implementation of mechanisms that lead to the prevention of the establishment of worms. The two main processes are the humoral response, involved in the recognition and processing of nematode antigens entering the system of an individual and the cellular response, which influences the recruitment of cells that actively destroy parasites [21]. Other feedback mechanisms lead to increased peristalsis of the gut, mucus entrapment and local inflammation, all of which actively aid the expulsion of worms [14].

Upon primary exposure to internal nematodes, memory cells are developed that facilitate faster immune reactions in secondary infections with worms of the same species. It is unclear if the genes that control key processes and mechanisms preventing the establishment of worms in primary infections of sheep with internal nematodes are different to those involved in subsequent infections. When parasite larvae reach their tissue niche in a naïve organism an immune response is triggered resulting in an increased recruitment of lymphocytes, eosinophils, $\mathrm{T}$ and $\mathrm{B}$ cells, with a concomitant delay in worm expulsion [3]. In comparison, in sheep that have been previously exposed to internal nematodes the larvae do not reach the tissue because an immediate immune response leading to expulsion is triggered with very little change to the cell populations [3]. Therefore it appears that different pathways are involved that may underlie the control of different genes. However, as Windon et al. [31] 
Table I. Phenotypic indicators for internal nematode resistance ([5,9]; Windon, pers. comm., 2004).

\begin{tabular}{lll}
\hline $\begin{array}{l}\text { Parasitological } \\
\text { indicator }\end{array}$ & Immunological indicator & Pathological indicator \\
\hline Faecal egg count & Serum antibodies (IgG1, & Plasma pepsinogen \\
Number of adult larvae & IgA and IgE) & concentration \\
& ELISA & Plasma albumin \\
& Western blotting & concentration \\
& Peripheral eosinophilia & Fructosamin concentration \\
& Mediator concentrations & Packed cell volume \\
& Histology (mast cells / & Dag score \\
& globule leukocytes, & Faecal consistency \\
& eosinophils, goblet cells) & \\
\hline
\end{tabular}

have shown, sheep can be successfully bred for overall increased or decreased resistance, based on selection criteria that are correlated with acquired immunity. This would support the hypothesis that innate and acquired resistance underlie similar genetic control mechanisms.

Resistance to internal nematodes is clearly a complex physiological characteristic and the activation of certain pathways depends on the previous exposure of the individuals to worm larvae. One hypothesis claims that any physiological or immunological indicator trait can only describe parts of the mechanisms involved [1] and therefore traits for internal nematode resistance measured after primary infection might not be useful in the measurement of resistance after secondary infection or vice versa. However, evidence from selection experiments [31,32] where overall resistance was achieved through selection for acquired resistance rather than resistance to primary exposure to worms, challenges this hypothesis.

Another level of complexity of nematode resistance is that indicator traits can be nematode specific, e.g. packed cell volume is a pathological indicator of anaemia, a trait which is suggestive of $H$. contortus, a blood sucking internal parasite, but not by other gastrointestinal nematodes. Therefore, in identifying QTL for parasite resistance it can be expected that the results will vary depending on the nematode species, the challenging regime and the indicator trait measured.

However, a number of phenotypic indicators have been shown to be useful in measuring internal nematode resistance in sheep. The main indicator traits are listed in Table I and are classified into three groups: parasitological, immunological and pathological traits [9]. 


\subsection{Analytical complexity}

The phenotypic assessment of internal nematode resistance generally follows artificial infection with nematode larvae to ensure a standardised exposure of individuals to the parasite. However, such challenge regimes do not guarantee equal infection of all animals. This can lead to inconsistencies in measurements, which can cause problems in the statistical analysis and may influence the results.

In particular, zero scores for indicator traits for nematode resistance pose difficulties in the statistical analysis of internal nematode resistance. Zero scores can occur for a variety of reasons and it is highly probable that these values will be misinterpreted. In order to define the risk of interpretation Tilquin [27] classified zero scores into four categories:

(1) True zero scores, where infected individuals cleared the infection through an effective immune response.

(2) True zero scores, as a result of the peak of infection being missed and due to the wrong timing of phenotype recording.

(3) False zero scores, due to non-detectable egg counts.

(4) False zero scores, due to missed infection as a result of the sheep not ingesting the larvae at the time of artificial infection.

In general zero scores cannot be avoided, but the challenge is to reduce the number of occurrences of false zero scores as defined previously, under (3) and (4).

Internal nematode resistance, measured as FEC, is generally a non-normally distributed trait. This characteristic can be compounded by a large number of zero scores leading to a distinct peak in the phenotypic distribution, causing it to be heavily skewed with a long tail. Tilquin et al. [28] described nematode resistance as a categorical trait with large numbers of categories.

The assumptions for QTL analyses include normality of the distribution of the trait analysed. Tilquin et al. [28] investigated the sensitivity of parametric and non-parametric QTL analysis approaches and concluded that loss in power of QTL detection is due to the non-normality of data and the occurrence of zero records. They also described that maximum likelihood and least-squares methods can lose up to 54\% of power in detecting QTL, if non-transformed data is analysed, concluding that the non-parametric method is the most robust analysis approach. Tilquin et al. [28] recommend that data like those obtained for FEC should be analysed with a non-parametric method or if parametric approaches are used the data are appropriately transformed to conform to the normality assumptions. 
Broman et al. [8] considered a spike in phenotypic distribution of the zero value with a two level analysis called "two-part model". The first part analyses non-zero records on a continuous scale to establish whether a QTL has an effect on the conditional mean. The second part treats the data as a binary trait (phenotype or no phenotype) and gives an indication of a QTL having an effect on the probability of individuals having a phenotype different from zero. Broman et al. [8] compared in their study four analytical approaches over eight simulated scenarios: the parametric two-part model, its individual component analysis, maximum likelihood and binary, and a nonparametric approach. The results showed that the component analyses have the greatest power in situations where a QTL influences either the conditional mean or the probability of having a phenotype. If there is an effect on both, the nonparametric test has greater power. However, the two-part model always performed second best and the overall average power over the eight scenarios was the highest. Therefore, Broman et al. [8] concluded that the two-part model is the most useful approach for the analysis of data with a spike in the phenotypic distribution, in particular if multiple QTL are considered.

\section{QTL FOR PARASITE RESISTANCE IN SHEEP}

The previous paragraphs illustrate some of the issues that make internal nematode resistance a complex and therefore difficult characteristic to measure and analyse. The complexity of the physiological processes suggests that a large number of genes are involved in the mechanisms that lead to nematode resistance. A large part of the research into nematode resistance has been undertaken in mice and they have served as a valuable model for internal nematode resistance in sheep [6]. The literature published on QTL in internal nematode resistance in sheep is limited in volume and has been based on diverse analysis approaches, sheep breeds and nematode species (Tab. II). Positions of markers reported in the following paragraphs were taken from the sex average ovine marker map published by Maddox et al. [18] on the Australian Sheep Gene Mapping web site.

Research conducted at Sydney University [25] and the University of New England [20] in Australia, has involved segregation analysis to investigate evidence for the segregation of a major gene for nematode resistance. Raadsma et al. [25] found evidence that a QTL for resistance to $H$. contortus was segregating within a flock of Indonesian Thin Tail $\times$ Merino cross animals based on FEC after primary artificial challenge. The findings were confirmed in a linkage analysis [25]. The Golden Ram project [20] found evidence for a QTL 
Table II. QTL for nematode resistance in sheep ordered by chromosome (Chr.).

\begin{tabular}{|c|c|c|c|c|c|c|}
\hline Chr. & Location & $\begin{array}{l}\text { LOD } \\
\text { score }\end{array}$ & Trait & Nematode species & Sheep breed & Ref. \\
\hline \multirow[t]{2}{*}{1} & $\begin{array}{l}\text { Proximal end } \\
\text { EPCDV010 }(22.7 \mathrm{cM})- \\
\text { ILSTSO44 }(67.7 \mathrm{cM})\end{array}$ & & $\begin{array}{l}\text { FEC } \\
\text { Nr. adult larvae }\end{array}$ & T. colubriformis & $\begin{array}{l}\text { New Zealand } \\
\text { Romney } \\
\text { selection lines }\end{array}$ & {$[13]$} \\
\hline & $\begin{array}{l}M c M 130(253.5 \mathrm{cM})-M c M 357 \\
(331.2 \mathrm{cM})\end{array}$ & 2.8 & $\begin{array}{l}\text { Mean FEC } \\
\text { (three counts) }\end{array}$ & T. colubriformis & $\begin{array}{l}\text { Merino divergent } \\
\text { selection lines }\end{array}$ & [4] \\
\hline \multirow[t]{3}{*}{3} & $\begin{array}{l}\text { IFNG region } B L 4(205.8 \mathrm{cM})- \\
\text { BMS1617 }(212.2 \mathrm{cM})\end{array}$ & & FEC & $\begin{array}{l}\text { Multi-species } \\
\text { challenge }\end{array}$ & $\begin{array}{l}\text { Romney } \\
\text { divergent } \\
\text { selection lines }\end{array}$ & {$[24]$} \\
\hline & First intron of the IFNG region & & IgA level & Te. circumcincta & Soay sheep & {$[11]$} \\
\hline & $\begin{array}{l}\text { TGLA67 }(90.4 \mathrm{cM})-\text { OarVH130 } \\
(216.1 \mathrm{cM})\end{array}$ & 3.9 & $\begin{array}{l}\text { FEC after secondary } \\
\text { challenge }\end{array}$ & T. colubriformis & $\begin{array}{l}\text { Merino divergent } \\
\text { selection lines }\end{array}$ & [4] \\
\hline 6 & $\begin{array}{l}\text { McMA22 }(112.4 \mathrm{cM})-M c M 214 \\
(140 \mathrm{cM})\end{array}$ & 4.2 & $\begin{array}{l}\text { FEC after primary } \\
\text { challenge }\end{array}$ & T. colubriformis & $\begin{array}{l}\text { Merino divergent } \\
\text { selection lines }\end{array}$ & [4] \\
\hline \multirow[t]{2}{*}{20} & DRB1 & & $\begin{array}{l}\text { FEC after natural } \\
\text { infection }\end{array}$ & Te. circumcincta & $\begin{array}{l}\text { Scottish } \\
\text { Blackface }\end{array}$ & {$[26]$} \\
\hline & $\begin{array}{l}\text { OarCP73 }(18.1 \mathrm{cM}) \\
D Y M S 1 \text { (position unknown) } \\
\text { BM1815 }(26.8 \mathrm{cM})\end{array}$ & & $\begin{array}{l}\text { Haematocrit level } \\
\text { IgL level } \\
\text { FEC after artificial } \\
\text { challenge }\end{array}$ & H. contortus & Roehnschaf & {$[17]$} \\
\hline
\end{tabular}


in the experimental flock using cube root transformed FEC collected four and five weeks after infection and for the mean of the two after secondary artificial challenge with $H$. contortus. The effect appeared to be large and explained one third of the variance in these traits. These results confirmed the hypothesis established by Gray [15] that parasite resistance is under the control of a major gene. Currently, the findings in the Golden Ram flock are being investigated further in a linkage analysis based on a full genome scan (Marshall, pers. comm., 2004)

As a result of linkage analyses two authors found evidence for QTL for internal nematode resistance traits on chromosome 1 [4, 13]. Diez-Tascon et al. [13] examined several phenotypic indicators for nematode resistance in New Zealand Romney selection lines. Eighteen microsatellite markers were spaced at an average distance of $20 \mathrm{cM}$ across chromosome 1. A significant relationship between the level of FEC of $T$. colubriformis and the number of adult larvae in the abomasum and a region at the proximal end of chromosome $1($ EPCDV010 $(22.7 \mathrm{cM})$ - ILSTS044 $(67.7 \mathrm{cM}))$ was found. This significant association was established in one sire group using a within family analysis. However, the significant chromosomal region was of low information content and the authors suggested more markers in the region of interest were required to confirm the result.

An experiment undertaken by Beh et al. [4] identified a region at the distal end of chromosome $1($ McM130 $(253.5 \mathrm{cM})-M c M 357(331.2 \mathrm{cM}))$ with chromosome wide significance (LOD $=2.8$ ) for mean FEC of three counts after secondary artificial challenge with $T$. colubriformis. Merino selection lines with high and low immune responses to T. colubriformis were used in the study and the top and bottom 25\% of the distribution for FEC were genotyped for 133 markers spaced across the whole sheep genome.

Other studies have found significant associations between phenotypic indicator traits of nematode resistance and regions on chromosome 3, [4, 11,24]. In a fine mapping study using Romney lines divergent for nematode resistance, Paterson et al. [24] found five significant markers in the Interferon gamma region (BL4 (205.8 cM) - BMS1617 (212.2 cM)) linked to FEC measured after artificial multi species challenge. The results could not be confirmed in the Perendale breed, but the hypothesis was established that the allele was fixed in this breed. However, despite being in a different linkage phase, the hypothesis could be confirmed in the Romney breed using industry data. A study on IgA level in Soay sheep measured after an artificial challenge with Te. circumcincta established a significant association with the first intron of the IFNG region on chromosome 3 [11]. 
Two flanking markers were established in a $10 \mathrm{cM}$ distance of that region as a control, however no significant association was shown with these markers. Beh et al. [4] found an interval (TGLA67 (90.4 cM) - OarVH130 (216.1 cM)) on chromosome 3 of $100 \mathrm{cM}$ with chromosome wide significance $(\mathrm{LOD}=3.9$ ) for FEC after secondary challenge with $T$. colubriformis.

Chromosome 6 showed a significant association at the genome wide significance level $(\mathrm{LOD}=4.2)$ between the region $(M c M A 22(112.4 \mathrm{cM})-M c M 214$ $(140 \mathrm{cM}))$ and FEC after primary challenge with $T$. colubriformis [4]. The same region was confirmed at chromosome wide significance $(\mathrm{LOD}=2.8$ ) for the same indicator trait following a secondary challenge. The major histocompatibility complex (MHC) is believed to be involved in the mechanisms of immune response that will eventually lead to resistance to internal nematodes. The MHC is located in the sheep genome on chromosome 20 [12]. Several studies have shown significant associations between regions on ovine chromosome 20 and indicator traits for internal nematode resistance [10,26].

The DRB1 locus [26] within the ovine MHC has been associated with resistance to Te. circumcincta in Scottish Blackface. However, in a different analysis of the data, the results were not confirmed and a microsatellite for the DY locus (DYA $13.5 \mathrm{cM}$ ) was found to be significant [10].

Janssen et al. [17] found the markers OarCP73 (18.1 cM), DYMS1 (position unknown) and $B M 1815(26.8 \mathrm{cM})$ to have a significant association with haematocrit level, IgL (L3 stage larvae specific immunoglobulin) level and log transformed FEC respectively following an artificial challenge with $H$. contortus.

The literature summarised in the previous paragraphs and in Table II outlines the diversity of approaches taken in QTL mapping experiments in sheep and the wide range of results reported. This might point at the involvement of different chromosomal regions in different pathways of nematode resistance depending on the indicator traits and challenging regime chosen in the studies.

\section{DISCUSSION}

Internal nematode resistance is an economically important trait for the sheep industries. It is a characteristic that is difficult to measure and therefore not easily included in breeding programmes. New technologies could be applied for breeding purposes if the genes involved in parasite resistance or markers that are closely linked to these genes can be identified. Marker or gene assisted selection or introgression of genes involved in the mechanisms of nematode resistance into highly productive, but parasite susceptible breeds, would accelerate the genetic improvement of resistance to internal nematodes. 
A number of studies have investigated QTL for internal nematode resistance in sheep $[4,10,11,13,17,24,26]$. However, the results of the studies differed in the chromosomal regions of interest that were identified to have significant associations with nematode resistance. This could be due to differences in experimental protocols and materials, differences in the analytical approaches or a combination of both. The studies differed in the sheep breeds and nematode species used in the experiments, the indicator traits for internal nematode resistance measured and the challenge regimes. Considering the complexity of the physiological processes of nematode resistance, it is not surprising that the studies did not yield the same results.

Most of the regions that have been identified as being significantly associated with indicator traits for nematode resistance in the different experiments vary between studies, with the INFG region on chromosome 3 being the exception. The region was identified to influence a significant proportion in the variance for nematode resistance traits by Beh et al. [4], Coltman et al. [11] and Paterson et al. [24].

The analytical approaches were different across studies. Most of them focused on single chromosomes [10,11,17,24,26], whereas Beh et al. [4] undertook a full genome scan and looked for significant associations between chromosomal regions and indicator traits of internal nematode resistance across the whole ovine genome. The authors of the different studies do not mention if the phenotypic data were tested for normality and how this data characteristic was dealt with. Potentially different approaches have been taken, which could have impacted on the power of detection of QTL and therefore on the results.

It can be concluded that the investigation of QTL for internal nematode resistance in sheep has been shown to be a difficult area of research, mainly due to a large number of problems associated with the phenotypic and analytical complexity of this characteristic. More consistency in protocols, experimental materials and analysis approaches would facilitate the generation of comparable results and the identification of genes or markers closely linked to genes that are associated with resistance to internal nematodes. However, the combination of mapping and candidate gene approaches and the advances in comparative genomics will assist in enhancing the progress in the detection of the genetic changes that influence the pathways of internal nematode resistance in sheep.

\section{REFERENCES}

[1] Albers G.A.A., Gray G.D., Breeding for worm resistance: a perspective, in: Parasitology - Quo vadit? Proceedings of the Sixth International Congress of 
Parasitology, Brisbane, 24-29 August, 1986, Australian Academy of Science, Australia, pp. 559-566.

[2] Baker R.L., Gibson J.P., Irqi F.A., Menge D.M., Mugambi J.M., Hanotte O., Nagda S., Wakelin D., Behnke J.M., Exploring the genetic control of resistance to gastrointestinal helminth infections in sheep and mice, in: Proceedings of the Association for Advancement in Animal Breeding and Genetics, 7-11 July, 2003, Vol. 15, Melbourne, Vic., Australia, pp. 183-190.

[3] Balic A., Bowles V.M., Meeusen E.N.T., The mechanisms of immunity to Haemonchus contortus infection in sheep, Parasit. Immunol. 24 (2002) 39-46.

[4] Beh K.J., Hulme D.J., Callaghan M.J., Leish Z., Lenane I., Windon R.G., Maddox J.F., A genome scan for quantitative trait loci affecting resistance to Trichostrongylus colubriformis in sheep, Anim. Genet. 33 (2002) 97-106.

[5] Beh K.J., Maddox J.F., Prospects for development of genetic markers for parasite resistance to gastrointestinal parasite infection in sheep, Int. J. Parasitol. 26 (1996) 879-897.

[6] Behnke J.M., Iraqi F., Menge D., Baker R.L., Gibson J., Wakelin D., Chasing the genes that control resistance to gastrointestinal nematodes, J. Helminthol. 77 (2003) 99-110.

[7] Bisset S.A., Vlassoff A., West C.J., Breeding sheep for resistance / tolerance to internal parasites, in: Practical aspects of internal parasites. Proceedings of the 21st seminar of the Sheep and Cattle Society, July, 1991, Vol. Pub. No. 134, Lincoln University, New Zealand, pp. 83-91.

[8] Broman K.W., Wu H., Sen S., Churchill G.A., R/QTL: QTL mapping in experimental crosses, Bioinformatics 19 (2003) 889-890.

[9] Buitkamp J., Bishop S.C., Stear M.J., The identification of sheep genetically resistant to the nematode Teledorsagia circumcincta, in: Proc. 7th World Cong. Genet. Appl. Livest. Prod., Montpellier, 19-23 August, 2002, Inra, CastanetTolosan, France, Communication No. 13-04.

[10] Buitkamp J.F.P., Stear M.J., Epplen J.T., Class I and class II major histocompatibility complex alleles are associated with faecal egg counts following natural, predominantly Ostertagia circumcinca infection, Parasitol. Res. 82 (1996) 693-696.

[11] Coltman D.W., Wilson K., Pilkington J.G., Stear M.J., Pemberton J.M., A microsatellite polymorphism in the gamma interferon gene is associated with resistance to gastrointestinal nematodes in a naturally-parasitized population of Soay sheep, Parasitol. 122 (2001) 571-582.

[12] Crawford A.M., McEwan J.C., Dodds K.G., Wright C.S., Bisset S.A., Macdonald P.A., Knowler K.J., Greer G.J., Green R.S., Shaw R.J., Paterson K.A., Cuthbertson R.P., Vlassoff A., Squire D.R., West C.J., Phua S.H., Resistance to nematode parasites in sheep: How important are the MHC genes?, in: Proceedings of the Association for Advancement in Animal Breeding and Genetics, Vol. 12, Dubbo, NSW, Australia, pp. 58-61.

[13] Diez-Tascon C., MacDonald P.A., Dodds K.G., McEwan J.C., Crawford A.M., A screen of chromosome1 for QTL affecting nematode resistance in an ovine outcross population, in: Proc. 7th World Cong. Genet. Appl. 
Livest. Prod., Montpellier, 19-23 August, 2002, Inra, Castanet-Tolosan, France, Communication No. 13-37.

[14] Emery D.L., McClure S.J., Wagland B.M., Production of vaccines against gastrointestinal nematodes of livestock, Immunol. Cell Biol. 71 (1993) 463-472.

[15] Gray G.D., Genetic resistance to Haemonchosis in sheep, Parasitology Today 3 (1987) 253-255.

[16] Gruner L., Aumont G., Getachew T., Brunel J.C., Pery C.Y., Guerin Y., Experimental infection of Black Belly and INRA 401 straight and crossbred sheep with trichostrongyle nematode parasites, Vet. Parasitol. 116 (2003) 239-249.

[17] Janssen M., Weimann C., Gauly M., Erhardt G., Associations between infections with Haemonchus contortus and genetic markers on ovine chromosome 20, in: Proc. 7th World Cong. Genet. Appl. Livest. Prod., Montpellier, 19-23 August, 2002, Inra, Castanet-Tolosan, France, Communication No. 13-11.

[18] Maddox J.F., Franklin I.R., Bottema C.D.K., DeSilva U., Adelson D.L., DiezTascon C., Nattrass G., Gill C., Webb G., Dodds K.G., Vaiman D., An enhanced sheep linkage map comprising 240 genes and EST associated markers http://rubens.its.unimelb.edu.au/ JILLM/jill.htm [consulted: 2004].

[19] McLeod R.S., Costs of major parasites to the Australian livestock industries, Int. J. Parasitol. 25 (1995) 1363-1367.

[20] Meszaros S.A., Henshall J.M., Burgess S.K., Gray G.D., Tier B., Detection of a quantitative trait locus associated with the reduction of faecal egg count in Merino sheep, in: Proceedings of the Association for Advancement in Animal Breeding and Genetics, 4-7 July, 1999, Vol. 13, Mandurah, WA, Australia, pp. 211-214.

[21] Miller H.R.P., Prospects for the immunological control of ruminant gastrointestinal nematodes: natural immunity, can it be harnessed?, Int. J. Parasitol. 26 (1996) 801-811.

[22] Mugambi J.M., Bain R.K., Wanyangu S.W., Ihiga M.A., Duncan J.L., Murray M., Stear M.J., Resistance of four sheep breeds to natural and subsequent artificial Haemonchus contortus infection, Vet. Parasitol. 69 (1997) 265-273.

[23] Nimbkar C., Ghalsasi P.M., Swan A.A., Walkden-Brown S.W., Kahn L.P., Evaluation of growth rates and resistance to nematodes of Deccani and Bannur lambs and their crosses with Garole, Anim. Sci. 76 (2003) 503-515.

[24] Paterson K.A., McEwan J.C., Dodds K.G., Morris C.A., Crawford A.M., Fine Mapping a locus affecting host resistance to internal parasites in sheep, in: Proceedings of the Association for Advancement in Animal Breeding and Genetics, 30 July-2 August, 2001, Vol. 13, Queenstown, New Zealand, pp. 91-94.

[25] Raadsma H.W., Maragawati E.T., Piedrafita D., Estuningsih E., Widjajanti S., Beriajaya, Subnadryio, Thompson P., Spitthill T.S., Towards molecular genetic characterisation of high resistance to internal parasites in Indonesian thin tail sheep, in: Proc. 7th World Cong. Genet. Appl. Livest. Prod., Montpellier, 19-23 August, 2002, Inra, Castanet-Tolosan, France, Communication 13-19. 
[26] Schwaiger F.W., Gostomski D., Stear M.J., Duncan J.L., McKellar Q.A., Epplen J.T., Buitkamp J., An ovine Major histocompatibility complex DRB1 allele is associated with low faecal egg counts following natural, predominantly Ostertagia circumcincta infection, J. Parasitol. 25 (1995) 815-822.

[27] Tilquin P., Indicator traits for mapping disease resistance traits: Methodological aspects of the mapping of disease resistance loci in livestock (Thesis), Université catholique de Louvain, 2003, pp. 83-106.

[28] Tilquin P., Coppieters W., Elsen J.M., Lantier F., Moreno C., Baret P.V., Statistical power of QTL mapping methods applied to bacteria counts, Genet. Res. 78 (2001) 303-316.

[29] Van der Waaij E.H., van Arendonk J.A.M., Introgression of genes responsible for disease resistance in a cattle population selected for production: genetic and economic consequences, Anim. Sci. 70 (1999) 207-220.

[30] Wanyangu S.W., Mugambi J.M., Bain R.K.D.J.L., Murray M., Stear M.J., Response to artificial and subsequent natural infestation with Haemonchus contortus in Red Maasai and Dorper ewes, Vet. Parasitol. 69 (1997) 275-282.

[31] Windon R.G., Dineen J.K., Wagland B.M., Genetic control of immunological responsiveness against the intestinal nematode Trichostrongylus colubriformis in lambs, in: McGuirk B.J. (Ed.), Merino improvement programs in Australia, Australian Wool Corporation, Melbourne, 1987, pp. 371-375.

[32] Woolaston R.R., Piper L.R., Selection of Merino sheep for resistance to Haemonchus contortus: genetic variation, Anim. Sci. 62 (1996) 451-460.

[33] Woolaston R.R., Windon R.G., Gray G.D., Genetic variation in resistance to internal parasites in Armidale experimental flocks, in: Gray G.D., Woolaston R.R. (Eds.), Breeding for disease resistance in sheep, Australian Wool Corporation, Melbourne, 1991, pp. 1-9.

To access this journal online: www.edpsciences.org 